\title{
OUR NATIONAL HEALTH AND RESEARCH POLICY: PROGRESSIVE CHANGES
}

\author{
Dear Reader,
}

The suspense and excitement in industry, trade and the stock market during budget time have largely disappeared in the past few years. Gone are the days when movement of manufactured goods was restricted and the tax officials were on the prowl during budget time and soon after. Backed by a strong mandate, this year's maiden budget by the Honourable Union Finance Minister, Smt. Nirmala Sitharaman, reinforces this government's continued efforts and plans to improve the health and well-being of the common man.

The emphasis on "Make in India", not only by the MSME sector, provides additional opportunities to the manufacturing pharmaceutical industry and the fledgling medical

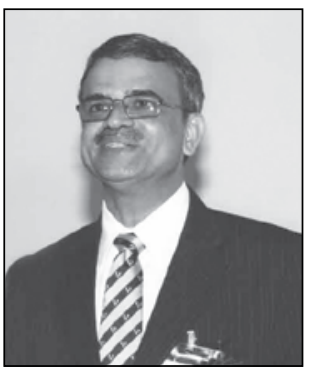
devices industry. The government's pro-active approach in using latest technologies across all sectors has contributed significantly to improve the effectiveness of its schemes (for example, direct benefit transfer of subsidies), though numerous challenges exist. The recently formed National Medical Devices Promotion Council certainly has its hands full and has surely not come a day too soon. At the same time, in today's world, we are not living in an insulated economy and industry cannot be protected from global influences beyond a limited extent. Thus, for example, if the Indian industry is not able to meet the expectations (price, quality and quantity, delivery) of medicines and medical devices, the doors will automatically get opened for imports. The example of imported LED bulbs being available at Rs. 60 apiece a few years ago through the intervention of the government when the price in the market was around Rs. 250 is still fresh in our minds.

With the Indian pharmaceutical industry being constantly pulled up as a source of counterfeit drugs sold across the world, the problem of counterfeit drugs is being countered head-on by using blockchain decentralized ledger and Internet-of-Things software in the real drug supply chain. It is hoped that this will bring accountability, speed and transparency in tracing and tracking drugs manufactured in India. NITI Aayog has partnered with the computer technology provider Oracle, the Apollo Hospitals Group and the pharmaceutical manufacturer Strides Pharma Sciences in a pilot project to this end. A few states, including Telangana with its excellent Transaction Management System, have pioneered this approach.

The challenges and opportunities of India's unique and ambitious health insurance scheme Ayushman Bharat for the hospital, diagnostic and pharmaceutical manufacturing industry are gradually becoming clearer. Providing quality health care with speed at an affordable cost across the length and breadth of federally-structured India is a daunting goal. Upgrading the primary healthcare centres, ensuring timely payment to the designated hospitals and suppliers of medicines and equipments as well as preventing likely corruption or misuse at different stages are the need of the hour. The lessons being learned in the field of healthcare from the 117 aspirational districts under, the Aspirational Districts Programme, are of great importance. Lupin (3) and Piramal (1) have, as is well known, "adopted" four such poor districts.

The impact of the Swachh Bharat Abhiyan "movement" over the last five years is having a positive impact on prevention and transmission of communicable diseases. The ambitious Jal Jeevan Mission with a focus to provide tap water to every household within the next five years will expand tremendously the benefits which the Swacch Bharat Abhiyan have given. It is today's school children across the country, having been made co-participants in such missions, who will ensure success and often educate their own parents on hygiene and cleanliness.

The proposal to establish a (hopefully autonomous) National Research Foundation "to fund, coordinate and promote research in the country" assumes great significance. With a plan to "assimilate the research grants being given by various ministries independent of each other", the government has been bold enough to accept that there are serious problems associated with the existing system of research funding by different ministries. With research and technology development becoming increasingly complex, demanding well-orchestrated efforts from various disciplines, institutions and institutes, it only makes sense to have 
a single organisation which has a national, global, unbiased and universal outlook, keeping the nation's priorities and aspirations in mind.

Take the hypothetical example of a research grant to develop chiral molecules from natural sources received from Ministry $A$. The research not only achieved the set goal, but also developed in the process a process for generating biofuel (Ministry B) and a process for biotechnology-based effluent/sewage treatment (Ministry $C$ ). The results also led to technology development for C3-C4-C5 molecules (Ministry D). The bio-waste generated from the research is of interest to Ministry E. Another Ministry (Ministry F) wants to support the project because biologically active molecules can be extracted from marine sources using some of the developed technology. Another ministry (Ministry G) wants to create light-weight materials for use in automobiles from the spent biowastes. Still another ministry (Ministry H) wants to support certain unique chemical engineering strategies which have spun off from the research. It is obvious that such an interrelated and interconnected project with all its benefits for the country at large cannot succeed if the researchers are busy applying for grants to seven or eight different ministries, writing reports and attending meetings all the time, rather than working in the lab and creating knowledge-based wealth.

We have also to learn from the positive and negative experiences gathered from the National Innovation Foundation, which was set up under the aegis of the Department of Science and Technology in 2000. The proposed NRF must focus on quickening the time required for research lab results to go commercial and on the relationship with industry partners, besides looking into more vigorous protection of the intellectual property created by the research of our scientists and engineers. The proposed NRF will certainly be studying the NRFs of countries like Singapore, South Korea, South Africa, Denmark, Germany and the United States while building up a potentially great Indian NRF.

Happy reading!

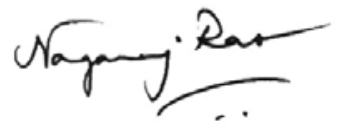

Dr. Nagaraj N. Rao Associate Editor

\section{About The Associate Editor}

Dr. Nagaraj Narayan Rao obtained Bachelor's degrees in Science (Chemistry) and in the Technology of Pharmaceuticals and Fine Chemicals from the University of Mumbai. After working with Colgate-Palmolive (India) for two years as a laboratory chemist, he obtained his doctorate in science with magna cum laude from the University of Tuebingen, Germany, under the guidance of Prof. Dr. H. J. Roth. He carried out post-doctoral research at the Institute of Biotechnology of the Research Center Juelich, Germany. He was a member of the Editorial Board for the first official German-language version of the European Pharmacopoeia. He was a visiting scientist at Juelich and a visiting faculty at the Institute of Chemical Technology Mumbai from 1993 to 2007 in the field of bioprocess technology. He has authored several original research articles, a patent, review articles and book chapters in the fields of pharmaceuticals, biotechnology, brewery and surface coatings. He was Chief Editor of the "Transactions of the MFAl" for a few years. He contributes a monthly 'Report from India' to a leading German technical journal since fourteen years and is a distinguished alumnus of the Research Center Juelich.

Dr. Rao is co-founder of the RRR group of small and medium enterprises, manufacturing organic fine chemicals, formulations for surface coating technologies and fertilizers, process sensors and process units for life sciences, brewery and chemical process industries, as well as representing select overseas companies for cell culture media, bulk drugs and used chemical equipment and plants. प1

If you would like to comment on the editorial please write to us at publications@idmaindia.com 